\title{
Territórios e adolescentes em conflito com a lei: existência, futuro e especificidades sociopolíticas
}

Territories and adolescents in conflict with the law: existence, future and socio-political specificities

\section{Maria Tereza Azevedo Silva mariaterezaazevedosilva@gmail.com Doutoranda em Psicologia Clínica.}

\section{Maria Helena Zamora}

zamoramh@gmail.com

Mestra e Doutora em Psicologia Clínica pela PUC-Rio. Professora associada do Departamento de Psicologia da PUC-Rio.

\section{Resumo}

Este artigo objetiva apresentar e interpretar dados coletados pela aplicação de um questionário on-line da pesquisa "Trajetórias de vida de jovens em situação de privação de liberdade no sistema socioeducativo do estado do Rio de Janeiro" (DEGASE; UFF,2018), sobre territórios de moradia de adolescentes em medida socioeducativa de internação. Pretende-se examinar aspectos de políticas públicas regionais, suas efetividades e demandas.

Palavras-chave: medida socioeducativa de internação; políticas públicas.

\begin{abstract}
This article aims to present and interpret certain data collected through the application of a online survey, from the research "Trajectories of life of young people in juvenile detention in the socio-educational system of the state of Rio de Janeiro" (DEGASE, UFF, 2018), about housing territories of these adolescents in socio-educational juvenile detention. It is intend to examine some regional public policies, their effectiveness and demands.
\end{abstract}

Keywords: socio-educational juvenile detention; public policy. 


\section{Introdução}

O conhecimento da população sobre um país é muito importante para compreender questões socioeconômicas de cada região e formular políticas públicas adequadas (IBGE, 2019). O Brasil alcançou em torno de 210.500.000 de habitantes, com uma taxa geométrica de crescimento de $0,79 \%$ ao ano, e na atualidade está em declínio quando comparada ao período entre os anos de 2017 e 2018 (IBGE, 2019). Apesar de ser um país populoso em termos absolutos, é pouco povoado; a população está concentrada, mais de sua metade, em 5,8\% de seus municípios. A região Sudeste é a mais populosa e povoada. Nela, a região metropolitana do Rio de Janeiro é a segunda mais populosa, alcançando 12,8 milhões de habitantes. A cidade do Rio de Janeiro fica em segundo lugar entre os municípios mais povoados (IBGE, 2019).

Neste trabalho, a população em foco é a de adolescentes em conflito com a lei, do sexo masculino, em cumprimento de medida socioeducativa de internação nas unidades socioeducativas do estado do Rio de Janeiro. Para além da delimitação de perfis que apontam seus delitos, pretende-se compreender a importância dos territórios de moradia e de sociabilidade em suas vidas. Para tal, serão utilizados dados de uma pesquisa realizada com adolescentes com o perfil apontado, "Trajetórias de vida de jovens em situação de privação de liberdade no sistema socioeducativo do estado do Rio de Janeiro" (DEGASE; UFF, 2018), que será descrita e comentada adiante, denominada a partir daqui como "Trajetórias".

É nas favelas que os adolescentes em privação de liberdade vivem, com “empobrecimento" não só dos recursos de vida, mas educacionais, culturais e sociais, além da extrema violência a que estão expostos e as discriminações diversas, inclusive o racismo. Existe um embate cotidiano e muitos são assassinados, de maneira cruel, sem que se consiga saber ao certo o que aconteceu nas suas vidas e com suas mortes.

Gonçalves (2013), assim como outros autores estudados, aborda as relações dos espaços favelados com as leis e as políticas sociais em períodos diferentes, apontando, entre outras questões, para a não inclusão sociopolítica desta população na cidade, apesar de todos os esforços dos próprios moradores. A entrada do tráfico, criminalizando muitas interações com o cotidiano da cidade, é associada ao o aumento da violência urbana. Tal percepção se mistura com a visão sobre os adolescentes deste espaço - em geral com dificuldades de subsistência e acesso a recursos públicos - como perigosos e envolvidos com atos infracionais. 
Este artigo está construído em quatro seções divididas: introdução, primeira seção, com uma abordagem inicial ao tema dos territórios, a pesquisa e sua relevância. A segunda seção busca contextualizar a relação entre a ocupação de territórios e os interesses sociopolíticos e econômicos que podem perpassar as políticas públicas oferecidas (ou não) nessas localidades. Na terceira seção, são apresentados dados da pesquisa "Trajetórias", pouco conhecidos, sobre esses adolescentes. Finalmente, na quarta, é apontada a existência de discriminações e lacunas que produzem uma realidade de profunda carência de parte da população, em diversos aspectos, bem como a premência de se pensar em políticas públicas eficazes nos variados setores da sociedade.

\section{Compreendendo territórios}

Raquel Rolnik em “Guerra dos Lugares” (2015) sublinha como um modelo neoliberal se entranha nas cidades e nas políticas urbanas e de moradia, produzindo um efeito excludente em seus moradores:

(...) capturando territórios, expulsando e colonizando espaços e formas de viver. Os efeitos desta colonização são político-territoriais, já que se trata também da emergência de uma nova forma de governo das cidades, denominada por alguns autores de pós-política ou pós-democrática, em que o dissenso e a negociação democrática são suprimidos em nome da eficiência e das tecnologias de governo. (ROLNIK, 2015, p.373)

Milton Santos, geógrafo brasileiro conhecido mundialmente, sublinha que o território habitado, espaço humano com a presença de objetos e ações, produz a criação de novas sinergias, provocando uma resposta à globalização e fragmentação (SANTOS, 1994, p.15-16). Ele aponta que o uso que se faz do território é que o torna um objeto de análise social; a compreensão de seu significado tem uma importância na direção de não se desconectar de seu sentido enquanto uma referência para os indivíduos em sua existência tanto individual como coletiva. $\mathrm{O}$ autor apresenta o território com horizontalidades e verticalidades, sendo as horizontalidades os domínios da contiguidade, os lugares vizinhos em continuidade territorial, e as verticalidades formadas por pontos distantes entre eles, e conectados por formas e processos sociais (SANTOS, 1994, p.16).

A presença de redes constitui parte deste espaço, havendo também, em simultaneidade, a presença do chamado espaço banal, aquele que é habitado e utilizado por todos, de formas diferentes ou similares, mas sem a configuração dada por qualquer forma de poder e DIGNIDADE RE-VISTA | ISSN2525-698X| 2020 | V. V | N. 10 | Um olhar para a Amazônia: riquezas e diversidades | Sessão livre. Pastoral Universitária Anchieta PUC-RIO. 
coexistindo com os lugares em rede, os lugares contíguos. Os lugares são os mesmos nos quais se formam as redes e o espaço banal, porém as funcionalidades são diferenciadas, podendo ser até opostas. Para Santos (1994), esta coexistência promove a possibilidade da criação de novas solidariedades independentes das diferenças entre as pessoas e os lugares e, para uma nova construção, precisam surgir novas horizontalidades partindo da base territorial para enfrentar a "globalização perversa", permitindo aos humanos um resgate de sua dignidade.

Santos (1991) sinaliza o papel privilegiado do espaço, que promove, através das interações existentes na atualidade, o encontro entre dois tempos: o passado e o futuro. A partir de um enfoque interdisciplinar, são ampliadas as chances de uma reconstrução da totalidade e, neste processo, o espaço pode cristalizar o passado e promover o encontro com o futuro, levando em conta as interações sociais presentes.

Maria Adélia Aparecida de Souza (1994) sublinha que os processos de globalização e fragmentação não se dão de forma aleatória, e sim com a implicação dos diferentes territórios que irão configurar as "geografias da desigualdade" (SOUZA, 1994, p.21). A autora aponta que, sendo uma dimensão do espaço geográfico, o território se constitui como uma base operacional, "histórica e geograficamente falando, do processo de globalização e fragmentação". Volta-se ao entendimento de uma relação particular entre espaço-tempo na qual se faz importante a distinção do território "como moeda e dimensão histórica deste eterno processo de globalização e fragmentação" (SOUZA, 1994, p.22). Sua visão foca-se na formação territorial do Brasil como um produto das relações sociais: a globalização atravessa as relações sociais e seu desenvolvimento.

Soares (2006), ao abordar a evolução urbana de uma cidade em seu processo produtivo sob um modelo protagonizado por um capitalismo sem limites, mostra que ocorre uma fragmentação e divisão de territórios de forma relacionada com a esfera social, alterando-se conforme interesses e poderes locais. O autor, ao estudar certas regiões de Salvador, Bahia, define "territórios populares" como:

(...) espaços, nos quais as condições de vida são precárias e neles imperam uma baixíssima presença do Estado. A desigualdade social como uma variável que se reflete no território gera espaços onde a situação de pobreza é homogênea, mas as práticas populares de se lidar com ela são bastante diversificadas (...) Espaços pobres, que apresentam características comuns entre si no que diz respeito à deficiência de acesso a equipamentos públicos e serviços. (SOARES, 2006, p.27) 
Soares (2006) aponta que a territorialização dos espaços inclui práticas e conteúdos sociais. Nos territórios comunitários encontramos histórias e hábitos compartilhados por seus moradores e acontece a construção de uma identidade social que assinala a forma singular de apropriação deste espaço. O território expressa muito sobre aqueles que o ocupam, as construções para lidar com os impasses e conflitos existentes se dão em uma criação coletiva de recursos compartilhados e que mantêm o vínculo comunitário (SOARES, 2006, p.27). A população que reside ou foi colocada em territórios populares pode vir a compartilhar estratégias para o acesso ao resto da cidade, desenvolvendo práticas para garantir sua identidade territorial investindo na consciência política e atuação efetiva.

\section{A pesquisa e sua relevância}

O sistema socioeducativo em todo o Brasil tem órgãos gestores, 26 estaduais e 1 distrital (DF), e para realizar a execução das medidas socioeducativas de privação e restrição de liberdade de adolescentes em conflito com a lei precisa ter um compromisso com a socioeducação nas diretrizes do Sistema de Garantia de Direitos do Estatuto da Criança e do Adolescente (BRASIL, 1990). Entre as exigências da política de atendimento socioeducativo está a determinação de que as unidades para internação e semiliberdade sejam construídas com alojamentos para acomodar adequadamente os adolescentes, devendo seguir uma lógica pedagógica e de segurança socioeducativa. As unidades de internação devem estar alinhadas com as diretrizes do Sistema Nacional de Atendimento Socioeducativo (Sinase), contendo em seu campo de atuação, além de suas acomodações, espaço para profissionalização, alimentação, descanso, prática de atividades esportivas, religiosas, atendimento técnico; deve ter também uma escola estadual, ligada à Secretaria Estadual de Educação para os jovens seguirem sua escolarização no período de privação de liberdade (BRASIL, 2012).

O Departamento Geral de Ações Socioeducativas (Degase), vinculado à Secretaria de Educação do estado do Rio de Janeiro, é o órgão responsável pela execução da medida socioeducativa de internação e semiliberdade para adolescentes em conflito com a lei no sistema socioeducativo do estado. $\mathrm{O}$ departamento, na atualidade, tem 9 unidades privativas de liberdade nas quais se executa a medida socioeducativa de liberdade e/ou internação provisória e conta com mais 15 unidades socioeducativas restritivas de liberdade.

O Degase tem como missão promover, em suas atividades e ações, a socioeducação no estado do Rio de Janeiro e sua meta implica investir na autonomia e protagonismo dos DIGNIDADE RE-VISTA | ISSN2525-698X| 2020 | V. V | N. 10 | Um olhar para a Amazônia: riquezas e diversidades | Sessão livre. Pastoral Universitária Anchieta PUC-RIO. 
adolescentes. Objetiva que, através do processo socioeducativo, os jovens possam se direcionar para se formarem cidadãos solidários, assim como estudar e se profissionalizar através da construção de projetos de vida e na preservação de sua convivência familiar e com seu coletivo territorial ${ }^{1}$. Os adolescentes ingressam no sistema apreendidos por cometimento de ato infracional e podem ser encaminhados para uma das medidas socioeducativas a partir dos 12 anos até 21 anos incompletos (BRASIL, 1990).

No ano de 2016, o Degase, através de sua gestão, solicitou à Assessoria de Sistematização Institucional (Asist), a realização de uma pesquisa institucional. O objetivo apresentado foi conhecer, através das falas dos adolescentes em cumprimento de medida socioeducativa de internação, como o sistema vem se apresentando, como é o cotidiano institucional para eles, como avaliam o processo socioeducativo desenvolvido em suas diversas áreas de atuação.

A partir da demanda institucional mencionada, foi construída, por uma equipe interdisciplinar e interinstitucional de pesquisadores da Asist e do Programa de Pós-graduação em Educação da Universidade Federal Fluminense, a pesquisa “Trajetórias de Vida de Jovens em Situação de Privação de Liberdade no Sistema Socioeducativo do Estado do Rio de Janeiro" que se desenvolveu entre os anos de 2016 e 2018 e foi realizada em seis unidades do sistema estadual, com cinco de adolescentes de sexo masculino e uma de sexo feminino (DEGASE; UFF, 2018, p.17-18). Uma das autoras deste artigo integrou a equipe de pesquisadores.

A pesquisa utilizou uma metodologia quantitativa através da análise de dados, resultante da aplicação de um questionário on-line aos participantes, com questões que abordavam diversos aspectos como o perfil dos adolescentes em suas características socioeconômicas, aspectos da escolarização e profissionalização, o embate com a violência em múltiplas facetas, a percepção das equipes dentro das unidades socioeducativas, entre outras questões como a singularidades e especificidades territoriais, estas últimas são o foco de nosso interesse. O relatório da pesquisa ${ }^{2}$ foi publicado no site do Degase. Os dados analisados da pesquisa "Trajetórias" (DEGASE; UFF, 2018) focaram na possibilidade de visualizar aspectos implicados com as trajetórias de vida dos adolescentes em medida socioeducativa de internação com suas famílias e territórios.

\footnotetext{
${ }^{1}$ Disponível em: http://www.degase.rj.gov.br/instituicao/quem-somos Acesso em: 12 abr 2020.

2 Disponível em: http://www.degase.rj.gov.br/files/pdf/pesquisa-jovens.pdf Acesso em: 12 abr 2020.
} 
Foi considerado um quantitativo de participantes, de cada unidade de internação, dado por cálculo estatístico, com confiabilidade de $95 \%$ nos resultados, alcançando para análise uma amostra de 307 questionários (DEGASE; UFF, 2018, p.14). A seguir, a figura 1 mostra como se dividem as regiões atendidas pelas unidades socioeducativas, apontando a abrangência da pesquisa de todo o estado do Rio de Janeiro:

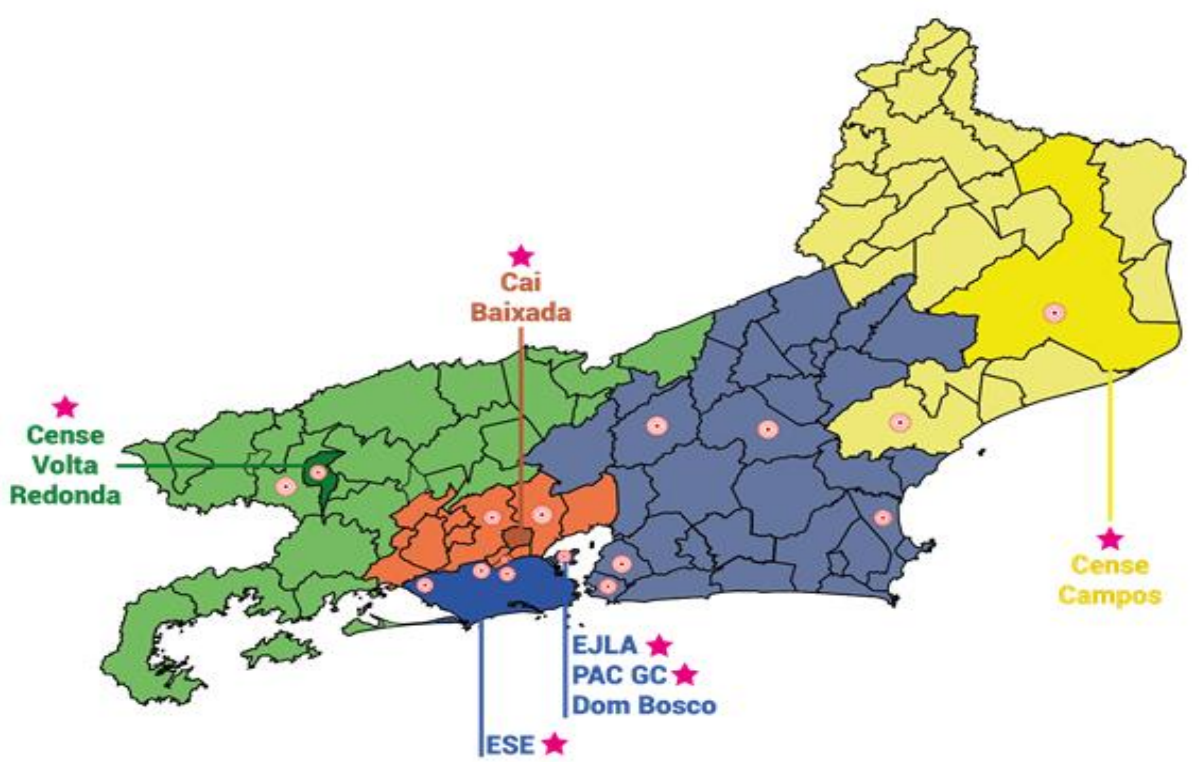

Unidades de internação onde a pesquisa foi aplicada ${ }^{*}$ Unidades de Semiliberdade

Figura 1: Regiões atendidas pelas unidades socioeducativas. Fonte: DEGASE; UFF, 2018.

A pesquisa traz um recorte dos territórios nos quais os adolescentes vivem quando em liberdade, sendo fato que se originam de diversos municípios, com contextos singulares. Estes jovens apresentam percepções acerca do local de convivência familiar e comunitária, permitindo um conhecimento da realidade local, de sua existência e vivência territorial enquanto cidadão e pertencente a uma sociedade que deveria incluir e não discriminar.

\section{O impacto das desigualdades}

Dados do IBGE (2016) apontam uma configuração percentual da população brasileira composta com mais de metade de autodeclarados pretos e pardos (negros) e a existência de uma concentração de menores rendimentos sendo recebidos por pessoas negras, com um percentual de $10 \%$ de pessoas com os menores rendimentos $-23,4 \%$ de brancos e $75,5 \%$ de pessoas negras. 
No estado do Rio de Janeiro, em indicadores recentes do Plano Nacional por Amostra de Domicílios, do IBGE, a população estimada ultrapassa o total de 17 milhões de habitantes (IBGE, 2019), entre os quais mais de 50\% são negros (pretos e pardos). No Levantamento Anual Sinase 2017 (BRASIL, 2019), o dado acerca de adolescentes considerados pretos e pardos (negros) em restrição e privação de liberdade, no país, apresenta em 2014 um percentual de 61\%, em 2016 de 59\%, e em 2017 foi de 56\% da amostra em questão.

No levantamento Sinase 2017, os dados do Degase assinalam o acompanhamento de um total de 1564 jovens em privação ou restrição de liberdade (1.531 adolescentes do sexo masculino), sendo o segundo estado do país com maior quantitativo de adolescentes, em um total nacional em torno de 20.000 adolescentes, sempre com larga predominância do sexo masculino e de cor negra ou parda (BRASIL, 2019, p.30). Em “Trajetórias", os dados apresentam um total de $96,7 \%$ de adolescentes do sexo masculino internados, com 76,2\% de cor negra ou parda (DEGASE; UFF, 2018, p.21-2), com um aumento do percentual.

Em sua maioria os jovens são advindos de condições precárias de subsistência: 30,4\% informaram ter uma renda familiar no valor de mais de três salários mínimos, porém $55,1 \%$ de adolescentes informam uma renda familiar que não alcança nem três salários mínimos, com um total de $24 \%$ recebendo até um salário mínimo. Considerando que $30 \%$ dos núcleos familiares são compostos de 6 componentes ou mais, a renda per capita variando entre R\$146 a 500 reais aponta o enfrentamento de baixas condições de subsistência (DEGASE; UFF, 2018, p.24).

Sobre a escolarização dos jovens, os dados (DEGASE; UFF, 2018, p. 35-38) são significativos: $25,7 \%$ dos adolescentes iniciaram seus estudos antes de completar 5 anos, $45,6 \%$ cursaram até a $5^{\mathrm{a}}$ ou $6^{\mathrm{a}}$ série do Ensino Fundamental e $34 \%$ afirmaram que por mais de 3 vezes repetiram de série. Em suas respostas, $58 \%$ declararam já ter tido problemas com professores e $30 \%$ afirmam não gostar de estudar. Um percentual de $61 \%$ de adolescentes estava fora da escola ao ser apreendido, deste total $63 \%$ estavam há mais de um ano afastados da escola, e 30\% responderam que, para ter interesse em voltar a estudar, precisariam encontrar perspectivas para ter verdadeiras chances de conseguir um bom emprego. Um dado positivo importante que também aponta para tal reflexão, visando que mudanças produtivas promovam uma diminuição do índice de abandono escolar, foi a percepção dos adolescentes sobre a escola: $96 \%$ acham muito importante e $97 \%$ querem que seus filhos estudem.

Observou-se uma entrada na vida laborativa bem cedo, em torno de $65 \%$ de adolescentes começando as atividades a partir de 10 a 15 anos de idade (DEGASE; UFF, 
p.26). E como uma referência de importância na vida dos adolescentes, o núcleo familiar constitui um espaço de interação afetiva e social que precisa também de atenção e suporte pelas políticas públicas para bem exercer seu papel (BRASIL, 2012) que remete à necessidade da integração sistemática do acompanhamento de suas famílias no processo socioeducativo (SILVA, 2018).

Uma grande parcela dos adolescentes em medida de internação no Rio de Janeiro vive em favelas (DEGASE; UFF, 2018, p.55). Silva et al., do Observatório de Favelas, compreendem que estes territórios são formados por:

Moradas singulares no conjunto da cidade, compondo o tecido urbano, estando, portanto, integrado a este, sendo, todavia, tipos de ocupação que não seguem aqueles padrões hegemônicos que o Estado e o mercado definem como sendo o modelo de ocupação e uso do solo nas cidades. $(2009, \mathrm{p} .21)$

Apontam os autores que os assentamentos em favelas, no decorrer do tempo, ficaram na ilegalidade e fora das normas existentes criadas por grupos hegemônicos. Estes espaços devem ter reconhecimento em suas singularidades socioterritoriais e servirem de campo para políticas públicas específicas. A favela é um território constituinte da cidade que enfrenta investimentos precários, estigmatizações socioespaciais, não seguimento de padrões nas construções, apropriação do território para moradia, baixos indicadores habitacionais, econômicos e ambientais, alto índice de desemprego de seus moradores, alta concentração de negros (pardos e pretos), alto grau de vulnerabilidade ambiental, entre outras características (SILVA et al, 2009, p.22-3).

Sobre elas, mesmo parecendo existir uma "tolerância" (GONÇALVES, 2013), ao não se definir, na gestão pública, por remoções de favelados, a presença do texto jurídico em torno destes espaços aponta, ainda hoje, a existência de uma lógica estigmatizadora. $\mathrm{Na}$ verdade, a utilização de estratégias pontuais em determinados momentos históricos, que surgem para controlar tensões sociais, funciona como uma flexibilização precária que não leva a resolução alguma, real e necessária.

Evidente que para o problema de as favelas serem regiões compostas por terrenos e construções em sua maioria não legalizados, a resolução seria alcançar a posse legal e patrimonial do território. Isso nunca foi solucionado integralmente, salvo em poucas regiões. Esta dita "tolerância" pelos poderes públicos com a manutenção das moradias sem legalização provoca e reforça a exclusão da população (GONÇALVES, 2013, p.3). Vale ressaltar também 
que a remoção, conforme interesses financeiros e políticos, ainda é muito utilizada, afastando moradores dos espaços mais valorizados no mercado imobiliário.

Em meados da década de 1980, ocorreu nas favelas um crescimento significativo do tráfico de drogas, com traficantes dividindo os territórios e ditando suas regras: “(...) impondo a lei do silêncio e do medo, influenciando diretamente ou indiretamente as diferentes relações sociais internas e rompendo toda e qualquer possibilidade de se federar os interesses dos favelados" (GONÇALVES, 2013, p.18).

Gonçalves (2013) assinala que o Estatuto da Cidade (Lei n¹0.257 de 2001) viabilizou uma melhor organização sobre o solo urbano e fortaleceu o sistema jurídico existente, pontuando a "função social da propriedade". A gestão municipal alcançou maior autonomia relativa às questões urbanas regionais, assim como a criação do Ministério das Cidades trouxe contribuições para promover a regularização fundiária das comunidades. Para o autor, é necessário um pacto sociopolítico elaborado dentro das diretrizes da Constituição de 1988 em seu paradigma jurídico-urbanístico inclusivo, com acesso à moradia para que se consolide, de fato, as favelas, com suas singularidades, como espaços integrados à cidade (GONÇALVES, 2013, p.21).

SILVA et al. (2009) em consonância com Gonçalves (2013) apontam para uma gestão metropolitana pautada por uma justiça territorial em que a cidade é vista de forma plural no reconhecimento da singularidade de cada espaço territorial e com seus moradores sendo respeitados como cidadãos através de políticas públicas a serem desenvolvidas em seus espaços.

No presente trabalho, como já dito, o foco é o território, com suas ofertas e faltas. Notese que, mesmo com tantas adversidades relatadas, 60\% dos adolescentes declararam não querer viver em outra região, não desejam se mudar.

Sobre o acesso a atividades culturais e de lazer, em relação ao teatro, a maioria dos jovens $(58,6 \%)$ não têm a oferta próxima ao seu local de moradia e apesar dessa afirmativa, $24,1 \%$ dos adolescentes tiveram acesso a esta atividade cultural. Em relação à existência de museus, $75,2 \%$ declaram não ter em suas regiões estas construções culturais, e um percentual de $15,6 \%$, de adolescentes já esteve em visita a um museu.

Os locais de shows apresentam percentual mais significativo de existência e acessibilidade, dentro do espaço territorial dos adolescentes, e 63,5\% respondem afirmativamente à sua existência na região de moradia. Os clubes também são parte deste 
SILVA, Maria Tereza Azevedo; ZAMORA, Maria Helena. Territórios e adolescentes em conflito com a lei: existência, futuro e especificidades sociopolíticas. Dignidade Re-Vista, v.6, n.10, jul 2020.

campo, 60,9\% declaram sua existência em seus espaços de moradia com fácil acesso (DEGASE; UFF, 2018, p.56).

Centros culturais estão na dimensão de 60,3\% de adolescentes afirmando que próximo a suas casas não há esta oferta, assim como os cinemas: 44,3\% dos entrevistados não têm acesso próximo; as quadras esportivas apresentam 91,5\% de afirmativa de existência próxima, com facilidade de acesso, assim como as praças, com um percentual de 96,7\% de existência nas regiões de residência. As praias não são nem de fácil acesso nem são próximas de $71 \%$ dos adolescentes, enquanto piscinas comunitárias são ofertadas, com $64,2 \%$ afirmando sua existência perto da residência. Este é um percentual a ser pensado, porque esta "generosidade" pode apontar para uma manobra de exclusão das classes menos privilegiadas de espaços frequentados pelos moradores de maior poder aquisitivo, como as praias (DEGASE; UFF, 2018, p.57).

Em relação a espaços de entretenimento social e comércio, a oferta de bailes é alta, $87,9 \%$, com acesso nas próprias comunidades, e os shoppings centers também têm alta oferta, $(61,2 \%)$ dos adolescentes têm acesso com facilidade a este espaço. Em contraponto, a existência dos projetos sociais para jovens de classes populares aparece com 50,1\%, porém $30,9 \%$ dos adolescentes afirmam ter acessado este serviço e 19,2\% nunca participaram.

Resumindo, as opções acessíveis de maior uso, em geral, situadas nos próprios territórios de referência habitacional, na área da cultura e de entretenimento, foram as praças, as quadras de esportes e os bailes. As opções com menor acesso foram os museus, o teatro e os centros culturais, espaços relacionados às classes mais abastadas em geral.

Acerca de recursos básicos, nas regiões de moradia dos adolescentes, um percentual de $74,6 \%$ de adolescentes declararam ter tratamento de esgoto, porém mais de $20 \%$ dos adolescentes não têm este recurso em suas residências; 89,6\% afirmam a existência de água encanada, ficando próximo a $10 \%$ de jovens sem este recurso; em relação à energia elétrica, quase a totalidade afirma ter o recurso; 97,1\%; a coleta de lixo alcança 93,1\% das regiões, $83,1 \%$ afirmam ter atendimento de emergência próximo à residência e 82,1\% afirmam que a área se mantém limpa na maior parte do tempo.

Sobre o acesso ao local onde moram, 41,3\% afirmam ser difícil de chegar, o que pode estar relacionado à sua exclusão. Entre os resultados, $81,6 \%$ declaram existir a prática de venda de drogas e atividades ilegais na região com a presença de conflitos armados, na própria comunidade, o que é afirmado por 71,6\%. A existência de fatores dificultadores nas 
regiões é enfrentada pelos moradores, e estes podem ser atraídos para atividades ilícitas, de forma contínua e presente, por diversos motivos (DEGASE; UFF, 2018).

Os indicadores da "Trajetórias" apresentados se confirmam em outros estudos que assinalam a questão da desigualdade social e de renda, não só da população do sistema socioeducativo, mas no Brasil inteiro. As fragilidades sociais relacionadas à educação, trabalho e renda ainda atingem profundamente parte da adolescência, alimentando vulnerabilidades vivenciadas pelos adolescentes em conflito com a lei: “(...) o fenômeno contemporâneo do ato infracional juvenil está associado não à pobreza ou à miséria em si, mas, sobretudo, à desigualdade social, e à dificuldade no acesso às políticas sociais de proteção implementadas pelo Estado" (SILVA \& OLIVEIRA, 2015, p.5).

\section{Considerações finais}

$\mathrm{Na}$ pesquisa, foi possível perceber que a maior parte das necessidades básicas apresentam algum atendimento pelo Estado, porém a manutenção e melhoria de suas instalações e ações, a erradicação da violência nesses espaços, a superação do racismo e exclusão social ainda apontam para uma necessidade de maior e melhor investimento nas políticas públicas para as áreas de referência de grande parte dos adolescentes do sistema socioeducativo do Rio de Janeiro e também da população mais empobrecida.

Considerando uma política de exclusão sociopolítico e cultural e em outros níveis presente em toda a história da cidade, os dados sinalizam a premência de se pensar no desenvolvimento de políticas públicas de inclusão. Investimentos públicos devem ser feitos em verdadeiras oportunidades para viabilizar a prática da cidadania de todo habitante da cidade, sem quebra de territórios, mas sim quebra de discriminação e exclusão. O estudo desenvolvido sobre parte dos resultados da Pesquisa "Trajetórias" (DEGASE; UFF, 2018) aponta para a necessidade de aprofundamento nos elementos inéditos para novos rumos e ações no campo socioeducativo. 


\section{Referências bibliográficas}

BRASIL. Estatuto da criança e do adolescente. Lei nº.069, de 13 de julho de 1990. Dispõe sobre o Estatuto da Criança e do Adolescente e dá outras providências. Diário Oficial [da República Federativa do Brasil], Brasília, DF, 1990. Disponível em: http://www.planalto.gov.br/ccivil_03/leis/18069.htm. Acesso em: 20 jun 2019.

. Estatuto da Cidade. Lei no 10.257, de 10 de julho de 2001. Regulamenta os arts. 182 e 183 da Constituição Federal, estabelece diretrizes gerais da política urbana e dá outras providências. Diário Oficial [da República Federativa do Brasil], Brasília, DF, 2001. Disponível em: http://www.planalto.gov.br/ccivil_03/LEIS/LEIS_2001/L10257.htm. Acesso em: 4 nov 2019.

Lei $\mathrm{n}^{\circ} 12.594$, de 18 de janeiro de 2012. Institui o Sistema Nacional de Atendimento Socioeducativo (Sinase). Disponível em: <http://www.planalto.gov.br/ccivil_03/_ato20112014/2012/lei/112594.html> Acesso em: 12 set 2019.

Levantamento Anual Sinase 2017. Brasília: Ministério da Mulher, da Família e dos Direitos Humanos, (MMFDH). 2019. Disponível em: <https://www.gov.br/mdh/ptbr/navegue-por-temas/crianca-e-adolescente/LevantamentoAnualdoSINASE2017.pdf> Acesso em: 31 mai 2020.

DEPARTAMENTO GERAL DE AÇÕES SOCIOEDUCATIVAS (Degase); UNIVERSIDADE FEDERAL FLUMINENSE (UFF). Trajetórias de vida de jovens em situação de privação de liberdade no sistema socioeducativo do estado do Rio de Janeiro. Rio de Janeiro: Degase; UFF, 2018.

FERNANDES, Fernando Lannes (org.) O que é favela, afinal? Rio de Janeiro: Observatório de Favelas do Rio de Janeiro, 2009. Disponível em <http://observatoriodefavelas.org.br/wpcontent/uploads/2013/09/o-que-\%C3\%A9-favela-afinal.pdf> Acesso em: 31 de mai 2020.

GONÇALVES, Rafael Soares. A política, o direito e as favelas do Rio de Janeiro: um breve olhar histórico. URBANA: Revista Eletrônica do Centro Interdisciplinar de Estudos sobre a Cidade, v.I, n.1, p.1-23, 2013.

. As favelas no Rio de Janeiro: história e direito. Rio de Janeiro: Pallas, 2013.

INSTITUTO BRASILEIRO DE GEOGRAFIA E ESTATÍSTICA (IBGE). Síntese de indicadores sociais: uma análise das condições de vida da população brasileira. Série Estudos e pesquisas. Informação demográfica e socioeconômica. Rio de Janeiro: IBGE, 2016.

Agência IBGE notícias. Rio de Janeiro, 28 ago 2019. Disponível em: <https://agenciadenoticias.ibge.gov.br/ agencia-sala-de-imprensa/2013-agencia-denoticias/releases/25278-ibge-divulga-as-estimativas-da-populacao-dos-municipios-para201S9> Acesso em: 12 set 2019.

ROLNIK, Raquel. Guerra dos lugares. A colonização da terra e da moradia na era das finanças. São Paulo: Boitempo, 2015.

DIGNIDADE RE-VISTA | ISSN2525-698X| 2020 | V. V | N. 10 | Um olhar para a Amazônia: riquezas e

diversidades | Sessão livre. Pastoral Universitária Anchieta PUC-RIO. 
SANTOS, Milton. A revolução tecnológica e o território: realidades e perspectivas. Terra Livre, n.9, p.7-17,1991. Disponível em: <http://www.agb.org.br/publicacoes/index.php/ terralivre/article/view/101> Acesso em: 21 jun 2019.

. O retorno do território. In: SANTOS, Milton; SOUZA, Maria Adélia Aparecida de;

OLIVEIRA, Maria Laura (orgs.). Territórios, Globalização e Fragmentação. São Paulo: Hucitec, 1994, p.15-20.

SILVA, Enid Rocha Andrade; OLIVEIRA, Raissa Menezes. O Adolescente em Conflito com a Lei e o Debate sobre a Redução da Maioridade Penal: esclarecimentos necessários. (Nota Técnica $\left.\quad \mathrm{n}^{\circ} 20\right)$. Brasília: IPEA, 2015.Disponível em: http://www.ipea.gov.br/portal/images/stories/PDFs/nota_tecnica/150616_ntdisoc_n20.

Acesso em: 21 jun 2019.

SILVA, Jailson de Souza e; BARBOSA, Jorge Luiz; BITETI, Mariane de Oliveira. O que é favela, afinal? Rio de Janeiro: Observatório das Favelas, 2009.

SILVA, Maria Tereza Azevedo. Família, socioeducação e projeto golfinhos: uma construção coletiva. Paraná: Appris, 2018.

SOARES, Antonio Mateus Carvalho. "Territorialização" e Pobreza em Salvador. Estudos Geográficos,v.IV, n.2, p.17-30, 2006. Disponível em: http://www.periodicos.rc.biblioteca.unesp.br/index.php/estgeo/article/view/202/175 Acesso em: 31 mai 2020.

SOUZA, Maria Adélia Aparecida de. Geografias da desigualdade: globalização e fragmentação. In: SANTOS, Milton; SOUZA, Maria Adélia Aparecida de; OLIVEIRA, Maria Laura (orgs.). Territórios, Globalização e Fragmentação. São Paulo: Hucitec,1994, p.21-8. 